\title{
Phase Transformations Evaluation on a UNS S31803 Duplex Stainless Steel based on Nondestructive Testing
}

Edgard de Macedo Silva ${ }^{1}$, Victor Hugo Costa de Albuquerque ${ }^{2}$, Josinaldo Pereira Leite ${ }^{2}$, Antonio Carlos Gomes Varela², Elineudo Pinho de Moura ${ }^{3}$, João Manuel R. S. Tavares ${ }^{4}$

${ }^{1}$ Centro federal de Educação Tecnológica da Paraíba (CEFET PB), Área da Indústria, Avenida $1^{\circ}$ de Maio, 720 - 58015-430 - João Pessoa/PB, BRASIL

Emails: edgard@cefetpb.edu.br

${ }^{2}$ Universidade Federal da Paraíba (UFPB), Departamento de Engenharia Mecânica (DEM), Cidade Universitária, S/N - 58059-900 - João Pessoa/PB, BRASIL

Emails: victor.albuquerque@fe.up.pt, josinaldo@ct.ufpb.br, varela@cefetpb.edu.br

${ }^{3}$ Universidade Federal do Ceará (UFC), Departamento de Engenharia Metalúrgica e de Materiais, Campus do Pici, Bloco 715, 60455-760 - Fortaleza/CE, BRASIL Emails: elineudo@pq.cnpq.br

${ }^{4}$ Faculdade de Engenharia da Universidade do Porto (FEUP), Departamento de Engenharia Mecânica e Gestão Industrial (DEMEGI) / Instituto de Engenharia Mecânica e Gestão Industrial (INEGI), Rua Dr. Roberto Frias, s/n, 4200-465 Porto, PORTUGAL Email: tavares@fe.up.pt

\section{Corresponding author:}

Prof. João Manuel R. S. Tavares

Faculdade de Engenharia da Universidade do Porto

Rua Dr. Roberto Frias, s/n

4200-465 Porto, PORTUGAL

email: tavares@fe.up.pt

Phone: +351 22 5081487, Fax: +351 225081445 


\title{
Phase Transformations Evaluation on a UNS S31803 Duplex Stainless Steel based on Nondestructive Testing
}

\begin{abstract}
Duplex stainless steel presents special mechanical properties such as, for example, mechanical and corrosion strength, becoming competitive in relation to the other types of stainless steel. One of the great problems of duplex stainless steel microstructural changes study is related to embrittlement above $300^{\circ} \mathrm{C}$, with the precipitation of the $\boldsymbol{\alpha}^{\prime}$ phase occurring over the ferritic microstructure. Aiming to characterise embrittlement of duplex stainless steel, hardening kinetics, from 425 to $475^{\circ} \mathrm{C}$, was analysed through the speed of sound, Charpy impact energy, X-ray diffraction, hardness and microscopy parameters. The presence of two hardening stages, detected through the speed of sound, was observed, one being of brittle characteristic and the other ductile. Moreover, the speed of sound showed a direct correlation with the material's hardness. Thus, it is concluded that the speed of sound is a promising nondestructive parameter to follow-up embrittlement in duplex stainless steel.
\end{abstract}

Key-words: Materials microstructure; Duplex stainless steel; Phase transformation; Rockweel C hardness; Aging time; Nondestructive testing; speed of sound; X-ray diffraction. 


\section{Introduction}

Materials embrittlement study has been performed through ultrasonic measurement, sound attenuation analysis, speed of sound and backscattered signal, as well as spectrum analysis. Microstructual variations cause the scattering of the sound wave causing an increased attenuation of the material. This technique's field of operation depends on the knowledge of the material's sound attenuation coefficient. However, the speed of sound variation is sensitive to the material's embrittlement. The application of this technique in practical situations depends on the accuracy of the material's thickness measurement One of the ways to eliminate the thickness measurement limitation is to determine a transversal and longitudinal relation between speeds, however the determination of this relation reduces the method's sensitivity, [1].

Another used technique is spectrum analysis which is caused by the reflections of sound on the material's microstructure. This technique is based on the analysis of the signal's frequency domain and its correlation with the microstructure. The studied interaction can be evaluated by the frequency distribution alteration of the transmitted or scattered ultrasonic pulse signal, [2].

The propagation of ultrasonic waves in polycrystalline materials are subject to interactions with microstructural components such as specks, inclusions, porosities, microcracks, corrosion, among others, causing sound attenuations and variation in the speed of sound propagation on the material in analysis, $[3,4,5]$.

The wave propagation speed and energy losses through interactions with the microstructure are the fundamental factors of the material's ultrasonic characterisation. These parameters may be used to determine elastic constants, microstructural analysis, texture, among other mechanical characteristics, [6]. 
The propagation rate of ultrasonic waves in any polycrystalline material is controlled by the material's elasticity module and density, being influenced by the microstructure, the change of the specks' elasticity module through the orientation of the specks' texture and second phase particles, [6].

Other mechanical tests such as, for example, hardness measurement and Charpy impact testing are also used to evaluate susceptibility in duplex stainless steel, [7].

Badidi et al., [8], has studied the effect of microstructural variation of martensite to ferriteperlite for steel with $0.4 \%$ of carbon, aimed at correlating the sound speed values with the material's hardness. It has obtained a direct correlation between hardness and sound speed. This relationship between sound speed and hardness was verified in Tane et al., [9], work, where duplex stainless steel JIS-SCS14A (CF8M) from $400^{\circ} \mathrm{C}$ with aging of $10 \mathrm{~h}$ was used as a sample.

As well as Badidi et al., Shigeyuki, [10, 11], has studied the same relationship between speed and the material's hardness using samples of duplex stainless steel aged at $475^{\circ} \mathrm{C}$. However, Shigeyuki did not obtain a direct relation between the sound speed values with the materials’ hardness and with an inverse correlation being observed.

Palanichamy, [12], studied the application of sound speed measurements for determining the speck size of austenitic stainless steels, since the materials' speck size influences countless mechanical properties, such as: mechanical, tensile and corrosion strength, yield point and toughness, among others. It was observed that the sound speed is affected by speck size, that is, an increase in speck size implies that the ultrasonic waves will take longer to cover the material's densities, causing the reduction in sound speed.

There are several variables to be analysed concerning the use of ultrasonic testing such as a microstructural inspection technique. A study of these nondestructive techniques will result in the development of procedures to follow-up operating pipes and, consequently, 
determining the best time to halt service for maintenance and the prevention of disasters which cause social and economic problems.

This research work aims at studying the kinetics of the precipitation of the spinodal decomposition $\boldsymbol{\alpha}^{\prime}$ phase on the embrittlement of duplex stainless steel (DSS) UNS-S31803 from 425 to $475^{\circ} \mathrm{C}$. Thus, it is possible to develop a nondestructive procedure to forecast, when operating, the best time to exchange or maintain duplex stainless steel piping. To do so, it is necessary to characterise, initially, the transformations which occur in steel through destructive testing such as, for example, X-ray diffraction, energy absorbed through Charpy impact and hardness. With the information obtained through these destructive tests, analyse, through nondestructive ultrasonic testing, its potentiality to characterise the kinetics of the microstructure’s transformation.

\section{Materials and methods}

The phase changes from 425 to $475^{\circ} \mathrm{C}$ for a duplex stainless steel UNS S31803, whose chemical composition is in Table 1, were studied.

To carry out the experimental part of our work, first it was necessary to apply thermal treatment on the DSS sample, aimed at evaluating the aging kinetics according to time and temperature exposure in the oven. In this context, the samples used were aged in an electric

resistance oven from 425 to $475^{\circ} \mathrm{C}$. Aging time used for each sample was 12, 24, 50, 100 and 200 hours.

After aging the samples, the hardness test, for analysing the behaviour of the effect of phase transformation, was performed. After that, Charpy impact testing was accomplished in order to evaluate the energy absorbed through DSS impact, as received and in the aging conditions, and a posterior analysis of each material's fracture surface. 
To study the formation of $\alpha^{\prime}$ phase an X-ray diffraction test was performed around the peak (200), the scanning angle (20) varied from 63 to $65.5^{\circ}$, for the treatment different types. An

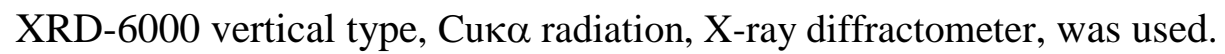

Ultrasonic testing was the nondestructive test used, applying the pulse echo method, with a normal V112-RM, 10.0 MHz longitudinal wave contact transducer manufactured by OLYMPUS. The tested samples’ dimensions were 55x25x10 mm.

The sound speed was determined by the relation:

$$
v=\frac{d}{t}
$$

where $d$ is the thickness of the sample and $t$ the time the ultrasonic signal takes to scan the sample's thickness and returns to the transducer. The time is determined through the overlapping of two consecutive peaks of the diagram tension versus time.

For the microstructural analysis of the received and aged material, the samples were prepared, polished and subjected to the electrolytic attack with oxalic acid. After this preparation, optical microscopy and scanning electron microscopy (SEM) were used to evaluate the microstructure of the received material and the fracture surfaces after Charpy impact testing.

\section{Results and discussions}

In this work the embrittlement kinetics of a duplex stainless steel UNS S31803, whose microstructure of the received material was obtained through optical microscopy as shown in Figure 1, was evaluated.

\subsection{Transformation of the microstructure from 425 to $475^{\circ} \mathrm{C}$}

The range of temperatures are characterised by the decomposition of the $\boldsymbol{\alpha}_{\text {initial }}$ phase in two phases, an $\boldsymbol{\alpha}$ phase poor in chromium and another $\boldsymbol{\alpha}$ ' phase rich in chromium. Spinodal 
decomposition, [13], is the mechanism responsible for this transformation. The $\gamma$ phase does not suffer transformation in this region, [14].

Aimed at establishing a correlation between the Rockewell C data hardness measurement, energy absorbed by Charpy impact, and aging time, graphics from these tests were obtained, as shown in Figures 2a and $2 b$, from 425 to $475^{\circ} \mathrm{C}$, respectively. Thus, the data analysis obtained for the transformations which occurred during aging become more accurate.

Figure 2a presents fast hardening for values up to 50 hours, followed by a region of low hardening rate. This occurred hardening kinetics at $425^{\circ} \mathrm{C}$ is slow. Figure $2 b$, in which hardening kinetics is faster, it is observed that the hardness curve may be divided in two hardening stages, the first up to the aging time of $24 \mathrm{~h}$ and the second from $50 \mathrm{~h}$ onwards, the mechanism responsible by hardening in each stage is later analysed through X-ray diffraction. The presence of two hardening stages was observed in other works which analysed the spinodal decomposition, as in Choo et al., [15], and Kratochvil et al., [16].

In Figure 2b, hardness increases rapidly in stage I, followed by a transition level between 24 and 50h. After that, stage II begins with a lower hardening rate and tending to a constant value, referring to the end of $\alpha$ phase formation. According to Choo et al., [15], the two hardening sources responsible for stages I and II are respectively the spinodal decomposition and the growth of the particles of the ordinate phase.

The behaviour of the material due to the energy absorbed by the Charpy impact testing is shown in Figures $2 \mathrm{a}$ and $2 \mathrm{~b}$. The first hardening stage is characterised by predominantly ductile fractures and microcavities, which characterise this mechanism, are observed at $425^{\circ} \mathrm{C}$, Figure 3a. Hardening in this stage is due to the process of ferrite transformation through spinodal decomposition. The second hardening stage, which starts at 50h, showed predominantly brittle fractures, in which it presence of almost cleavage fracture regions is 
observed, as indicated, by arrows, in Figure 3b. These fracture regions are related with the $\alpha$ ' ordinate phases growing, which, in time, tend to line up throughout the directions $\{100\}$, [17].

At $475^{\circ} \mathrm{C}$, the two stages are well defined, the first stage is characterised by ductile fracture and the second by brittle fracture. This was observed at $425^{\circ} \mathrm{C}$.

The arrangement of $\boldsymbol{\alpha}^{\prime}$ phase was analysed through X-ray diffraction in the peak (200). The presence of side strips, resulting from the arrangement of phases due to the spinodal decomposition mechanism, has been observed through diffraction of the selected area through Transmission Electronic Microscopy and X-ray diffraction, [17, 18, 19].

The peak (200) intensity variation study reveals that samples aged at $425^{\circ} \mathrm{C}$, Figure 4, show a peak reduction relative intensity to values up to 24 hours. According to Acselrad et al., [20], this aging band corresponds to the spinodal decomposition area. However, the first stage terminates within 50 hours, indicating that there are still more regions in decomposition. When this decomposition concluded, the second stage, with the growth of these particles begins. These stages, as already presented, are also observed at $475^{\circ} \mathrm{C}$.

The relative intensity reduces due to the peak's scattering (200), as rich and poor chromium regions grow and provoke the appearance of side strips which widen the peak and reduce its relative intensity, $[18,21]$.

The phase transformations were followed-up from 425 to $475^{\circ} \mathrm{C}$ through sound speed measurements. At $425^{\circ} \mathrm{C}$ (Figure $5 \mathrm{a}$ ) and $475^{\circ} \mathrm{C}$ (Figure $5 \mathrm{~b}$ ), it is observed that there is a direct relationship between sound speed and hardness. This indicates that the sound speed is capable of following-up the phase transformations which occurred in the two hardening stages.

Shigeyeiki et al., $[10,11]$, performed studies at $475^{\circ} \mathrm{C}$ in duplex stainless steel samples, and found that sound speed measurements were promising to follow-up the aging kinetics at this temperature. 
The sound speed varies inversely to the behaviour of absorbed energy. In Figures 6a and $6 \mathrm{~b}$, an accented decline of the absorbed energy, tending to a well defined level of brittle fracture, is observed at $425^{\circ} \mathrm{C}$ and $475^{\circ} \mathrm{C}$, respectively. In these figures, the sound speed for samples without treatment is $5.743 \mathrm{~m} / \mathrm{s}$ and it is also observed that in the brittle fracture level the speed increases to $5.786 \mathrm{~m} / \mathrm{s}$. This variation also indicates that the sound speed is sensitive to microstructures transformations.

Badidi et al., [22], observed that the microstructure variation and hardness are correlated with the sound speed and regarding the thinner steel microstructure, the larger is the contours surface quantity, increasing the material's hardness and consequently the sound speed will be greater.

In materials where the microstructural transformation is caused by the spinodal decomposition mechanism, during decomposition of the $\alpha^{\prime}$ phase there is a formation of alternate regions rich and poor in chromium. Regions enriched in chromium are responsible for the rigidity alteration of the iron matrix, provoking the increase of sonic speed values. When the first period concluded, the spinodal decomposition region ends and the $\alpha$ ' phase growth begins, this $\alpha^{\prime}$ phase is consolidated at the end of the second hardening stage. With that, the rigidity becomes constant, and a baseline for sound speed values is observed.

\section{Conclusions}

The UNS S31803 duplex stainless steel embrittlement study was performed in the band of 425 and $475^{\circ} \mathrm{C}$. The transformations' analysis was based on X-ray diffraction measurements, optical microscopy, scanning electron microscopy, sound speed measurements, Charpy impact and hardness tests.

The observations performed allowed the following conclusions: 
1) The studied duplex stainless steel showed two hardening stages. The first hardening stage is characterised by the spinodal decomposition mechanism and the second by the growth of the formed phases.

2) The first hardening stage is characterised by ductile fracture and the second shows low levels of absorbed energy and predominance of brittle fracture, characterising an embrittlement region of the material.

3) The variations of the sound speed measurements are directly proportional to the variation of the material's hardness measurements, showing sensitivity to the transformation phases. Thus, the sound speed is an important nondestructive parameter for following-up the hardening kinetics of duplex stainless steel.

\section{References}

1. Kruger, S.E., Rebello, J.M.A. and de Camargo, P.C. Hydrogen damage detection by ultrasonic spectral analisis. NDT\&E International, 1999, 32(5): 275-281.

2. Russel, M.D. Experimental estimation of longitudinal backscatter coeficiente for ultrasonic interrogation of weak scattering materials. The Journal of the Acoustical Society of America, 1993, 3: 1267-1276.

3. Kruger, S.E. Aplicação da análise espectral de ecos e do sinal retro espalhado na detecção de danos por hidrogênio em aços. In XIV Congresso de Pesquisa e Inovação da Rede Norte Nordeste de Educação Tecnológica, 1995, 72-79.

4. Bhattacharyya, S., Das, M.B. and Sarkar, S. Failure analysis of stainless steel tubes in a recuperator due to elevated temperature sulphur corrosion. Engineering Failure Analysis, 2008, 15(6): 711-722.

5. Kumar, M.S., Sujata, M., Venkataswamy, M.A. and Bhaumik, S.K. Failure analysis of a stainless steel pipeline. Engineering Failure Analysis, 2008, 15(5): 497-504.

6. Berger, H. Nondestructive Characterization of Materials: The Challenge of the 1990's. Materials Evaluation, 2000, 50(2): 299-305. 
7. Tavares, S.S.M, Noronha, R.F., Silva, M.R., Neto, J.M. and Pairis, S. $475{ }^{\circ} \mathrm{C}$ Embrittlement in a Duplex Stainless Steel UNS S31803. Materials Research, 2001, 4(4): 237-240.

8. Badidi, A., Benchaala, A. and Alem, K. Ultrasonic characterization of material hardness. Ultrasonics, 2000, 38: 224-227.

9. Tane, M., Ichitsubo, T., Ogi, H. and Hirao, M. Elastic property of aged duplex stainless steel. Scripta Materialia, 2003, 48: 229-234.

10. Shiegeyuki, H.W. Ultrasonic detection of thermal embrittlement of duplex stainless steel. International Conference on Nuclear Engeneering, 2000, 5: 215-223.

11. Shigeyuki, M., Hiroshi, M., Kazuhiro, M., Jun, S., Takuichi, I. Kumada, M., Kurosumi, Y. and Okano, Y. Ultrasonic detection of thermal embrittlement of duplex stainless steel. International Conference on Nuclear Engineering, 1996, 5: 215-223.

12. Palanichamy, P., Joseph, A., Jayakumar, T. and Raj, B. Ultrasonic velocity measurements for estimation of grain size in austenitic stainless steel. NDT\&E International, 1995, 28(3): 179-185.

13. Iacoviello, F., Casari, F. and Gialanella, S. Effect of “ $475{ }^{\circ} \mathrm{C}$ embrittlement” on duplex stainless steels localized corrosion resistance. Corrosion Science, 2005, 47(4): 909-916.

14. Mathew, M.D., Lietzan, L.M., Murty, K.L. and Shah V.N. Low temperature aging embrittlement of CF-8 stainless steel. Materials Science and Engineering A, 1999, 269(1): 186-196.

15. Choo, W.K., Kim, H.J. and Yoon, J.C. Microstructure changes in austenitic Fe-30.0 wt\% Mn-7.8 wt\% Al-1.3 wt\% C initiated by spinodal decomposition and its influence on mechanical properties. Acta Materialia, 1997, 45(12): 4877-4885.

16. Kratochvíl, P., Mencl, J., Pešička, J. and Komnik, S.N. The structure and low temperature strength of the age hardened Cu-Ni-Sn alloys. Acta Metall, 1984, 32(9): 1493-1500.

17. Mebed, A.M., Koyama, T. and Miyazaki, T. Spinodal decomposition existence of the $\beta$ Ti-Cr binary alloy: computer simulation of the real alloy system and experimental investigations. Computational Materials Science, 1999, 14(1-4): 318-322.

18. Miyazaki, T. and Koyama, T. Theoretical analysis of phase decomposition in real alloy systems based on the non-linear diffusion equation. Mater Transaction JIM, 1996, 37(4): 684-690.

19. Kalashnikov, I.S., Litvinov, V.S., Khadyyev, M.S. and Chumakova, L.D. The fine structure of FeMnAlC austenite after aging. Phys. Met. Metall., 1984, 57(6): 1216-1219. 
20. Acselrad, O., Kalashnikov, I.S., Silva, E.M., Khadyev, M.S. and Simao, R.A. Diagram of phase transformations in the austenite of hardened alloy Fe-28\% Mn-8.5\% Al-1\% C$1.25 \% \mathrm{Si}$ as a result of aging due to isothermal heating, Isothermal Transformation Diagrams. Metal Science and Heat Treatment, 2006, 48(11-12): 543-553.

21. Kalashinikov, I.S., Kibalnik, V.D., Litvinov, V.S. and Maliyenko, Y.E.I. Structure deviation in a high-strength 90G28Yu9MVB steels at the early stages of aging. Structure and properties of non-magnetic steels, 1986: 83-88.

22. Badidi, A., Lebaili, S. and Benchaala, A. Grain size influence on ultrasonic velocities and attenuation, NDT\&E International, 2003, 36(1): 1-5.

\section{Acknowledgments}

The work here presented was partially done in the scope of the research projects of Grupo de Simulação de Comportamento de Materiais (GSCmat) of Centro Federal de Educação Tecnológica da Paraíba (CEFET PB), and financially supported by CNPq - Brazil. 


\section{FIGURE CAPTIONS}

Figure 1 - Optical microscopy of the DSS as received, electrolytic attack with oxalic acid (Magnification: 1000X).

Figure 2 - Variation of the Rockwell C hardness measurements and the energy absorbed in the impact, due to the aging time at a) $425^{\circ} \mathrm{C}$ and b) $475^{\circ} \mathrm{C}$.

Figure 3- Fracture Surface a) 50 hours, and b) 100 hours of the samples treated at $425^{\circ} \mathrm{C}$ (Magnifications: 500X).

Figure 4 - Relation between peak (200) relative intensity and Rockwell C hardness for samples aged at $425^{\circ} \mathrm{C}$.

Figure 5 - Variation of sound speed and Rockwell C hardness according to aging time, at a) 425C and b) $475^{\circ} \mathrm{C}$.

Figure 6 - Variation of sound speed due to energy absorbed in the impact, with aging time, at a) $425^{\circ} \mathrm{C}$ and b) $475^{\circ} \mathrm{C}$. 
TABLE CAPTION

Table 1 - Duplex stainless steel composition as received. 


\section{FIGURES}

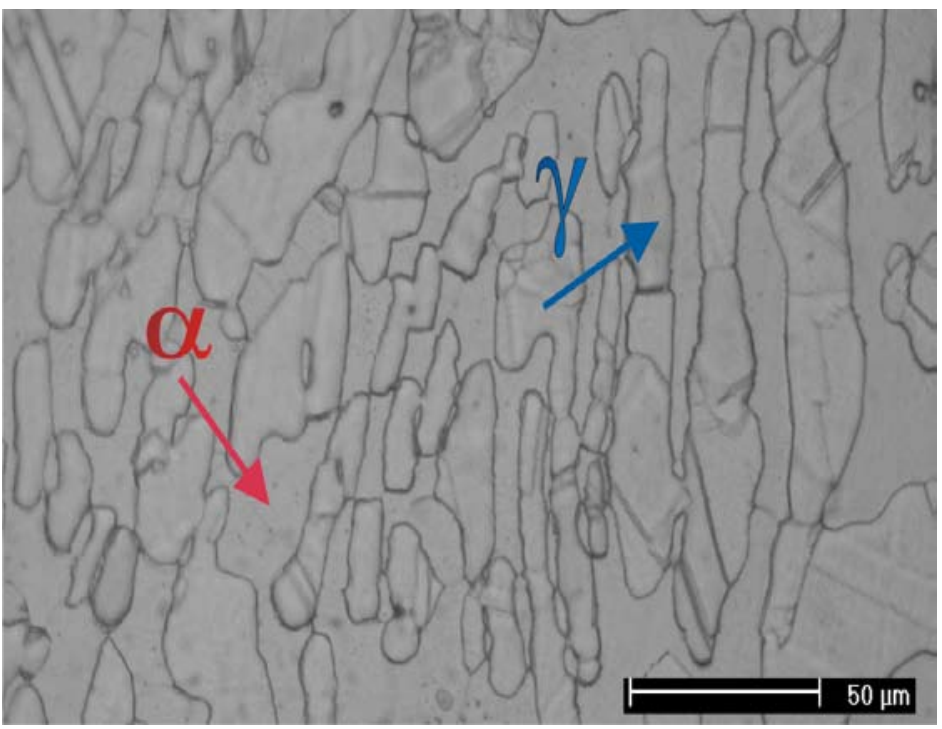

Figure 1

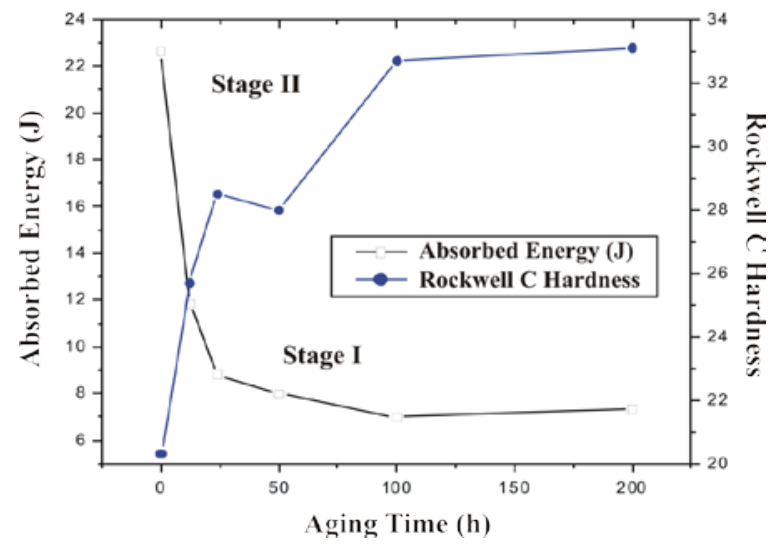

Figure 2a)

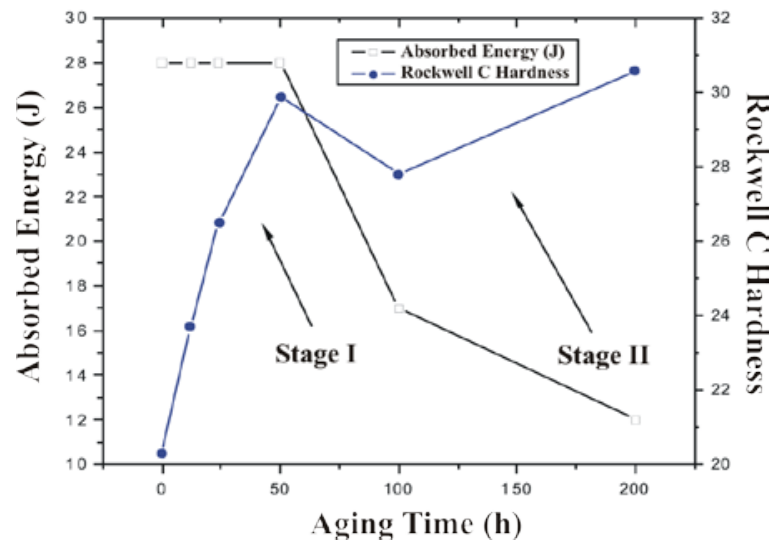


Figure 2b)

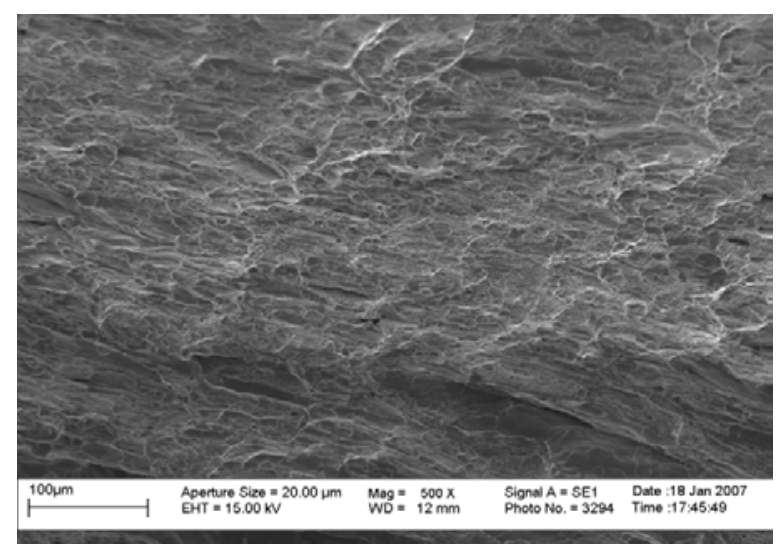

Figure 3a)

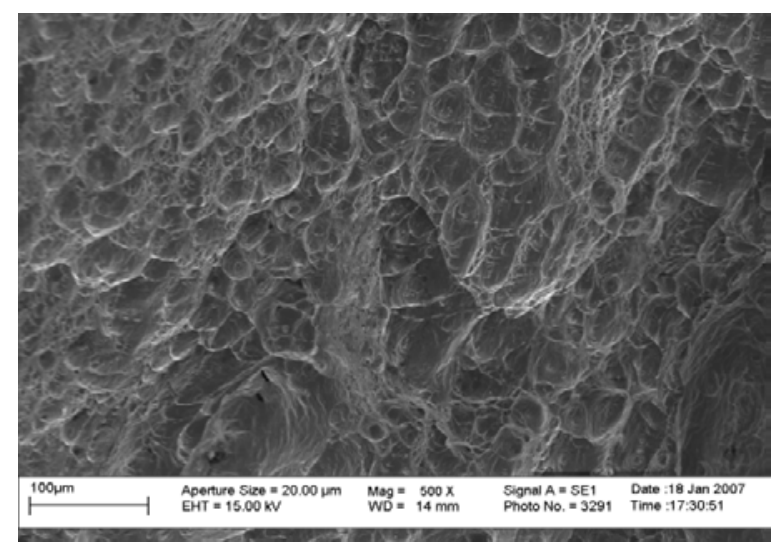

Figure 3b)

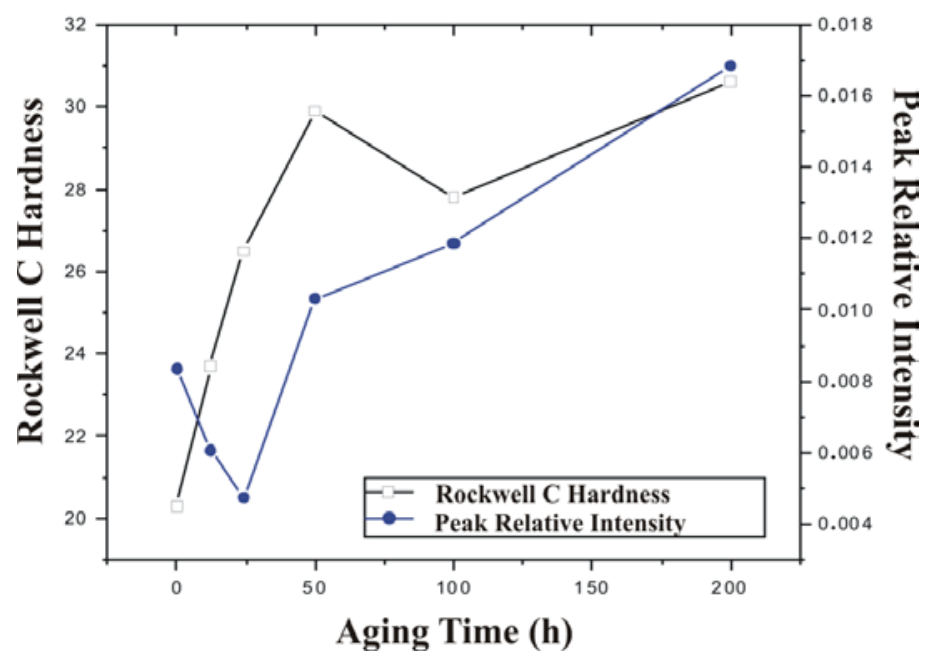


Figure 4

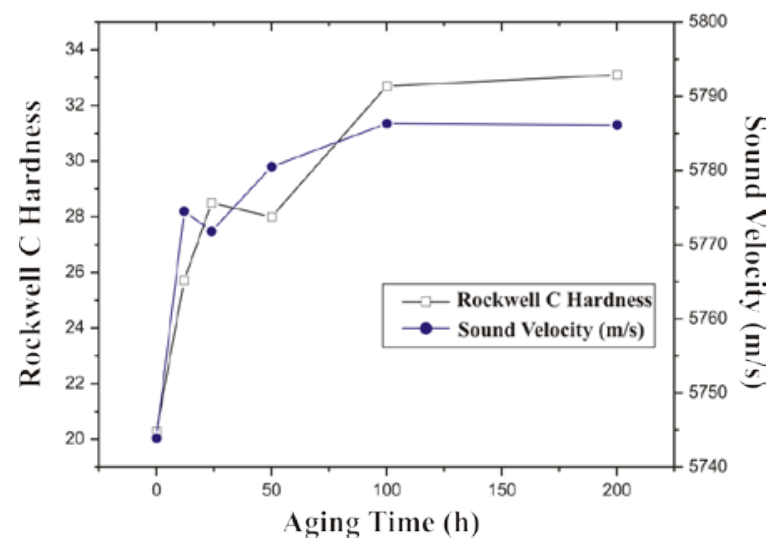

Figure 5a)

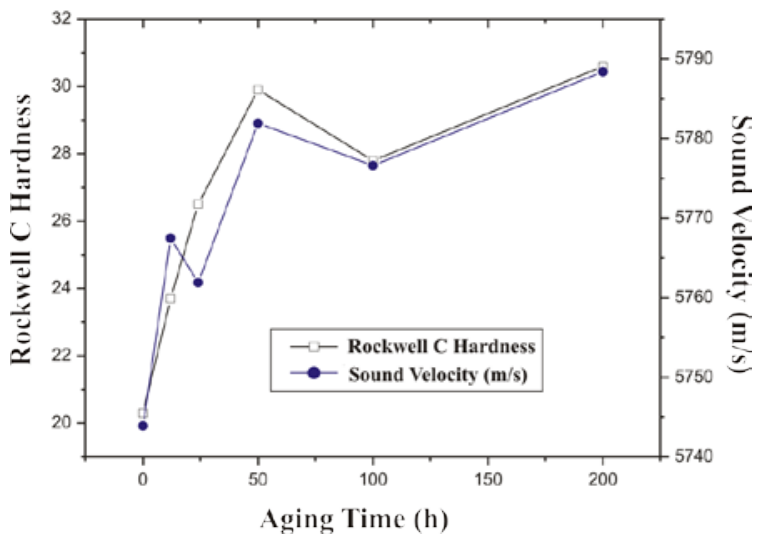

Figure 5b)

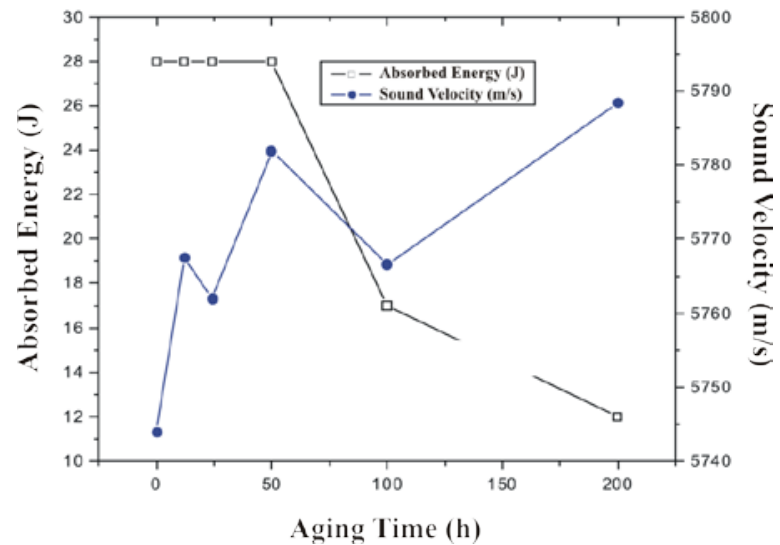

Figure 6a) 


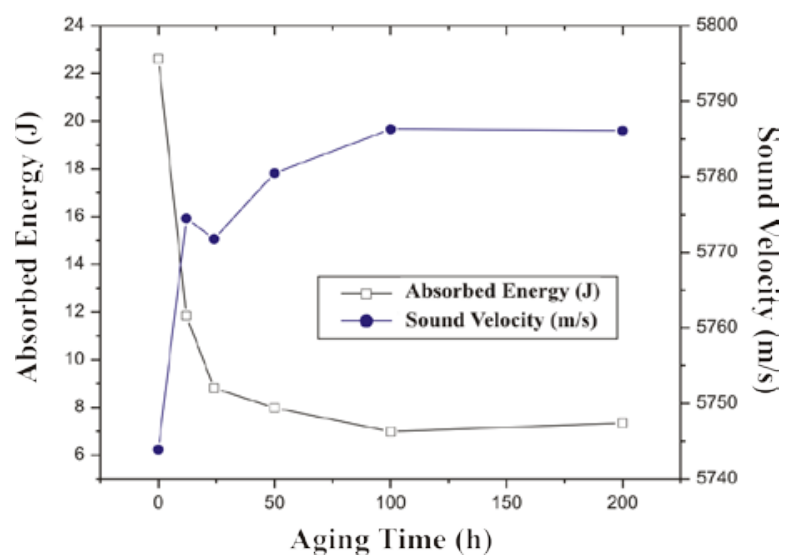

Figure 6b) 
Table 1 - Duplex stainless steel composition as received.

\begin{tabular}{|c|c|c|c|c|c|c|c|}
\hline \multicolumn{8}{|c|}{ Duplex Stainless Steel UNS-S31803 } \\
\hline $\mathbf{C}$ & Mn & $\mathbf{P}$ & $\mathbf{S}$ & Si & $\mathrm{Cr}$ & $\mathbf{N i}$ & Co \\
\hline 0.018 & 1.480 & 0.019 & 0.001 & 0.450 & 22.220 & 5.590 & 0.130 \\
\hline $\mathbf{C u}$ & Mo & $\mathbf{N}$ & $\mathbf{N b}$ & Al & Sn & Ce & $\mathbf{F e}$ \\
\hline 0.280 & 3.080 & 0.180 & 0.021 & 0.003 & 0.012 & 0.020 & 66.496 \\
\hline
\end{tabular}

